\title{
Influence of Chip Materials on Charge Generation in Flowing Solution in Nanobiosensors
}

\author{
Yuri D. Ivanov ${ }^{1, *} \mathbb{C}$, Andrey F. Kozlov ${ }^{1}$, Rafael A. Galiullin ${ }^{1}$, Vadim Yu. Tatur ${ }^{2}$, \\ Nina D. Ivanova ${ }^{3}$ and Vadim S. Ziborov ${ }^{1,4} \mathbb{D}$ \\ 1 Institute of Biomedical Chemistry, Moscow 119121, Russia; afkozlow@mail.ru (A.F.K.); \\ rafael.anvarovich@gmail.com (R.A.G.); ziborov.vs@yandex.ru (V.S.Z.) \\ 2 Foundation of Perspective Technologies and Novations, Moscow 115682, Russia; v_tatur@mail.ru \\ 3 Skryabin Moscow State Academy of Veterinary Medicine and Biotechnology, Moscow 109472, Russia; \\ ninaivan1972@gmail.com \\ 4 Joint Institute for High Temperatures of the Russian Academy of Sciences, Moscow 125412, Russia \\ * Correspondence: yurii.ivanov@rambler.ru; Tel.: +7-499-246-3761
}

Received: 25 December 2018; Accepted: 12 February 2019; Published: 16 February 2019

Featured Application: The effects of chip materials on charge generation in flowing aqueous solution should be taken into account in the development of highly-sensitive nanobiosensors, whose sensitivity is significantly influenced by the charge state of proteins and protein solutions, and also in the development of specified models of effects occurring in biosensors.

\begin{abstract}
Nowadays, nanobiosensors are being intensively developed due to the potential possibilities of their use for early diagnosis of diseases. This interest is enhanced by the fact that, as is known, a pathological process at an early stage is characterized by the appearance of marker proteins at very low $\left(10^{-15} \mathrm{M}\right.$ and lower) concentrations in blood. Highly-sensitive nanobiosensor systems (including those based on an atomic force microscope, AFM) allows one to detect proteins at such low concentrations. The influence of the charge generated in the analyte solution flowing through the biosensor injector into the measuring cell during measurements is considered to be an important factor conditioning such a high detection sensitivity. In the present study, it was demonstrated that the presence of an AFM chip (made of mica and graphite) near the nozzle of the injector supplying an analyte solution into the measuring cell of the AFM-based fishing system (AFM-based nanobiosensors) causes an increase in charge generation upon the injection of the solution. Moreover, the influence of polymer materials (which are widely used in nanobiosensors) and communications on charge generation in the flow-based section of AFM-based nanobiosensors was studied. A stimulating influence of a low (femtomolar) concentration of proteins on the charge generation in polymeric injectors of flow-based nanobiosensors was demonstrated. Besides, a stimulating influence of an external low-frequency AC electric field on the charge generation in the nanobiosensor injector was found. Measurements were carried out in the temperature range corresponding to the physiological temperature $\left(35^{\circ} \mathrm{C}\right)$.
\end{abstract}

Keywords: atomic force microscopy; polymer surface; graphite; mica; protein fishing

\section{Introduction}

One of the problems of further development of proteomics and medical diagnostics is to increase the sensitivity of protein registration methods. This is particularly important in the case of early diagnosis of diseases (including oncological and viral ones), when the analysis sensitivity must be at the level of femtomolar concentrations, corresponding to the concentrations of disease-associated marker proteins [1]. 
Nanobiosensor systems for proteomics and medical diagnostics, such as those employing atomic force microscope (AFM)-based fishing and nanowire detectors (i.e., the systems, in which molecular detectors are employed), allow one to register single viral particles and protein molecules with ultra-high sensitivity in counting mode [2-5]. These systems use an approach based on the introduction of an aqueous solution of an analyte (protein or virus) through an injector using either a pipette or flow system into a measuring cell containing a nanochip; analyte particles are captured onto the nanochip surface (i.e., fishing of the analyte occurs), where they are registered with molecular detectors in counting mode. In our previous paper [6] it was reported that by using systems for AFM-based fishing (that is, the systems, in which protein particles are captured from a large volume onto a small area of a chip for an atomic force microscope) it is possible to detect proteins at femtomolar and subfemtomolar concentrations upon feeding the protein solution into the measuring cell using an injector. As one of the factors of such a high efficiency of protein detection, the effect of charge generation in the analyte solution during its flow through an injector is considered. It is known that an electric charge is generated during the injection of a solution through a pipette tip [7]. At the same time, according to Reference [2], in a nanobiosensor system for AFM-based fishing at femtomolar and subfemtomolar protein concentrations, we observed a tendency for it to increase the number of captured protein molecules with the increase in the charge generated upon injection of analyzed solution into a measuring cell. External pulsed voltage applied to the measuring cell, was previously used by us to induce electric fields in flow-based systems for AFM-based fishing in order to enhance their sensitivity (up to the subfemtomolar level), as was demonstrated in Reference [6]. Thus, to enhance the efficiency of protein capturing in an AFM-based fishing system, it is important to study the phenomenon of charge generation during the flow of an aqueous solution through a flow-based system in various conditions. It is to be noted that the generation of charge during the flow of water and aqueous solutions along various surfaces [8], as well as changes in the physicochemical properties of water upon its flowing through polymer injectors [9], were long and widely discussed in the literature. In our previous paper [10], we demonstrated that negative pulsed voltage applied to parallel metal plates, between which an injector of the AFM-based fishing system was located, led to an increase in the efficiency of charge generation in the injector. At the same time, we demonstrated that an external AC electric field (with $50 \mathrm{~Hz}$ mains frequency, which is often present in biosensor devices) caused an increase in efficiency of charge generation in water flowing through an injector at a low-grade fever temperature $\left(38^{\circ} \mathrm{C}\right)$ [11]; this temperature is higher than that of phase transition of water related with heat capacity $\left(36.6^{\circ} \mathrm{C},[9]\right)$ and corresponds to a pathology in human.

Attention to the effect of materials, which are not directly contacting with flowing aqueous solutions, is usually given from the viewpoint of controlling the charge generation in a flowing solution with an external electric field. In this way, in Reference [12], the impact of the external electric potential of a closed metal ring on the generation of charge that occurs upon injection of a solution through this ring (which is not in contact with the liquid) is discussed. At the same time, the influence of materials of chips and communications on charge generation that are not in contact with the solution on the generation of charge in the solution flowing through the injector of the AFM-based fishing system is virtually not discussed in the literature. Also, it is known that the presence of macromolecules at low concentrations (including femtomolar ones) can influence the physicochemical properties of water (particularly, electrical conductivity, $\mathrm{pH}$, surface tension, [13,14]. In the literature, it is discussed that these effects can be connected with the transitions between ortho- and para-states of water owing to pumping of mixed quantum states of ortho-/para- $\mathrm{H}_{2} \mathrm{O}$ with natural and anthropogenic electromagnetic radiation (at which analytical biochemical measurements are usually carried out) [15]. In this connection, it is interesting to study not only the influence of the presence of proteins at low concentrations on charge generation of the AFM-based fishing system, but also the influence of external electromagnetic fields.

In systems for AFM-based fishing, AFM chips fabricated from mica or graphite are commonly employed. Communications fabricated from polymer materials (particularly polypropylene) are also 
often used in nanobiosensors. For this reason, in our present work, the influence of materials of chips and communications on charge generation in a biosensor based on a system for AFM-based fishing in its flow section (described in Reference [6]) was studied.

Stimulating influence of AFM chips, fabricated from mica and graphite, on charge generation in the injector section of a system for AFM-based fishing was demonstrated. The effect of an increase in the efficiency of charge generation in the flow section of nanobiosensors can well be influenced by polymer materials (particularly, those used in fluidic communications). At that, this efficiency depends on the completeness of filling of these communications with analyzed aqueous medium (water and/or aqueous protein solutions) used throughout the operation of nanobiosensors. The possibility of influence of highly dilute protein solutions (with concentrations in the range of $10^{-15} \mathrm{M}$, what is the range of operation of highly sensitive biosensors) on the stimulation of charge generation in polymeric injector of flow-based biosensor systems has been noted. The influence of external low-frequency $(50 \mathrm{~Hz})$ AC electric field, applied to the injector of the system for AFM-based fishing, has also been studied. Similar to References $[10,11,16]$, this field has been induced by negative AC voltage applied to electrodes, between which the injector was located. The temperature of $\mathrm{T}=35^{\circ} \mathrm{C}$ was selected due to the following considerations. Firstly, this temperature is lower than the temperature point of phase transition related to heat capacity [9]; secondly, this temperature is within the range of physiological temperatures of the human body, and this is the temperature of operation of biosensors upon studying biochemical processes in the human body in near-native conditions. These effects should be taken into account in the development of highly sensitive systems, whose operation is influenced by the charge state of analyzed solution.

\section{Materials and Methods}

\subsection{Materials}

Deionized water (18 $\mathrm{M} \Omega \times \mathrm{cm}$ resistivity) was obtained using a Simplicity UV system (Millipore, Molsheim, France). Fatty acid-free bovine serum albumin (BSA) (Sigma, St. Louis, MO, USA, cat. No. A6003) was dissolved in deionized water at $10^{-4} \mathrm{M}$ concentration; $10^{-15} \mathrm{M}$ protein solution was prepared by serial tenfold dilution of initial $10^{-4} \mathrm{M}$ solution. Muscovite mica $(25 \times 75 \times 0.25 \mathrm{~mm}$ sheets) was purchased from Structure Probe, Inc. (West Chester, PA, USA). Highly oriented pyrolytic graphite (HOPG, ZYH grade, $10 \times 10 \mathrm{~mm}$ plates) was purchased from NT-MDT (Zelenograd, Russia).

\subsection{Charge Measurements}

To investigate the influence of materials of chips and communications on the charge generation in the injector of the AFM-based biosensor (which is described in detail in Reference [6]), the corresponding chips or communications were placed near the injector used to supply the liquid into the measuring cell. The experimental setup is shown in Figure 1. The measurements of the electric charge were carried out with an electrometer coupled to the flow-based system for feeding the sample into the measuring cell (4) (Figure 1).

The main elements of the sample supply system were: the peristaltic pump, the pipe with a tip (the injector of part of the AFM-fishing biosensor system for supplying a solution), and the measuring cell. During measurements, water or protein solution from a 50-mL polypropylene tube (1) was continuously pumped through the tip (6) into the cell (4) with an Ismatec ISM 597D peristaltic pump (IDEX Corp., Lake Forest, IL, USA) (3). A sterile silicone pipe (2,5) (length $40 \mathrm{~cm}$, inner diameter $2 \mathrm{~mm}$ ) with a tip (6) was used to supply the analyzed liquid. The tip used was a standard disposable tip for an automatic pipette (inner diameter $0.4 \mathrm{~mm}, 10 \mu \mathrm{l}$ nominal capacity, epT.I.P.S, Eppendorf, Germany). The flow rate $(\sim 15 \mu \mathrm{l} / \mathrm{sec})$ was selected so that droplets would form on the tip nozzle. The calculated drop volume was $\sim 15 \mu \mathrm{l}$. To maintain the potential of the initial solution at a constant ground level, a ground electrode was inserted into the analyzed liquid in polypropylene tube (1). The stainless-steel cell (4) served as an internal cylinder in a system coupled to an electrometer (7). The dimensions of 
this cell were as follows: height $90 \mathrm{~mm}$, inner diameter $75 \mathrm{~mm}$, outer diameter $77 \mathrm{~mm}$, and thickness of the polypropylene insert between the outer and the inner plates was $0.2 \mathrm{~mm}$. In general, the system for charge measurements was similar to the one used in Reference [5]. The charge in the cell was registered using an electrometer (7) developed in Institute of Biomedical Chemistry (IBMC, Moscow, Russia). The charge of the studied materials (mica and polypropylene) was registered upon the introduction of these materials in the measuring cell of the electrometer. The charge registration accuracy was $0.1 \mathrm{nC}$. The influence of materials of AFM chips (mica and HOPG) and of material commonly used in fluidic communications (polypropylene) on the charge generation was investigated by comparative analysis of the charge generated in the injector (6) in the presence and in the absence of these materials. As a fragment of polypropylene tube, a 50-mL polypropylene tube, modeling a polypropylene communication, was used. The studied materials were placed at a certain distance $l(4 \mathrm{~mm}$ or $1 \mathrm{~cm})$ from the injector nozzle in position (8) (Figure 1). In Figure 1, (8) indicates the position of the chips (from mica or graphite) or the polypropylene tube relative to the injector nozzle. To study the influence of the external low-frequency electric field on the charge generation in the injector, the injector was placed between two parallel metal plates, and AC voltage (negative half sine wave, $100 \mathrm{~V}$ amplitude, $50 \mathrm{~Hz}$ frequency) was applied to the plates (similar to Reference [11]). The distance between the plates was $1 \mathrm{~cm}$. A generator developed in IMBC was used to supply the AC voltage. The temperature of water and protein solution was maintained using a thermostat, where a tube (1) containing the analyzed liquid was placed. The experiments were performed at $35^{\circ} \mathrm{C}$. Prior to the measurements, the system was equilibrated under the experimental conditions for at least $2 \mathrm{~h}$. The duration of one measurement was 5 to $7 \mathrm{~min}$. The air humidity was $45 \%$. The experimental series for each set of parameters included at least three repetitions.

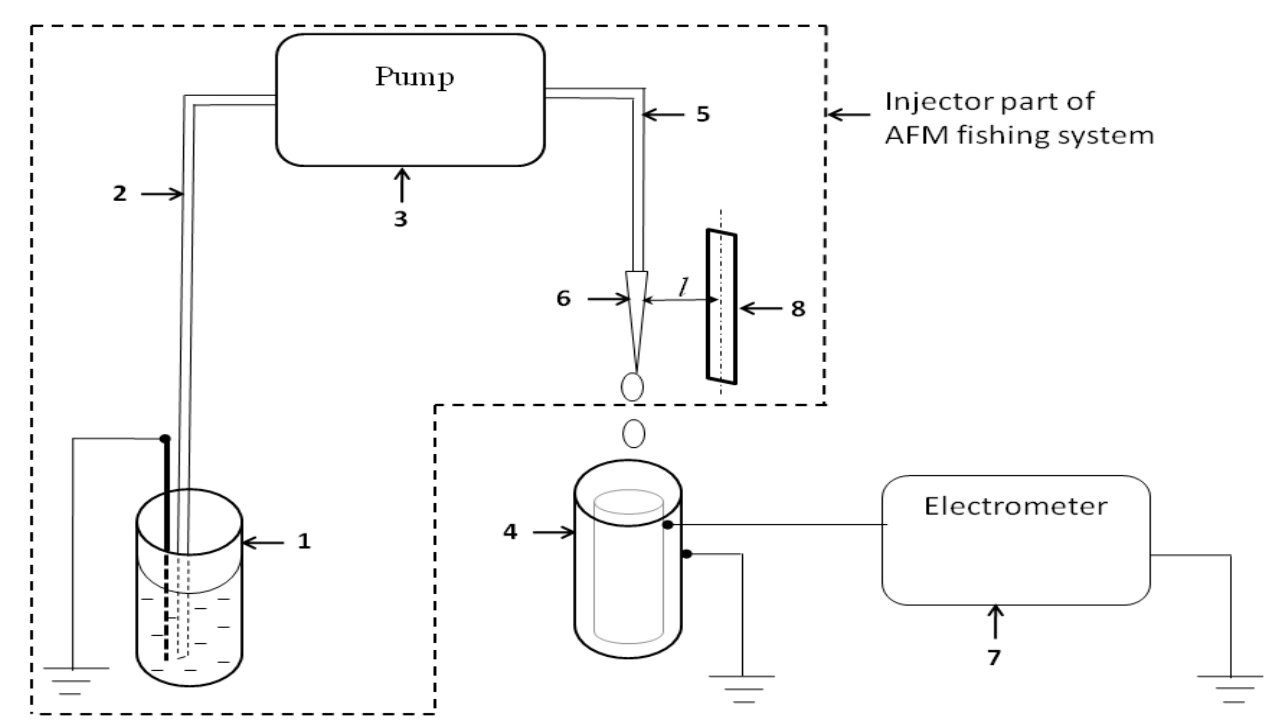

Figure 1. Experiment setup. (1) Measuring cell with analyzed liquid; (2) Silicone pipe (incoming section); (3) Peristaltic pump; (4) Measuring cell coupled with electrometer (7); (5) Silicone tube (outgoing section); (6) tip; (7) electrometer; (8) Investigated material. The investigated material (8) was either an atomic force microscope (AFM) chip (mica or graphite) or polypropylene tube; this material was fixed in a holder near the nozzle of the injector (8) at a distance $l=4 \mathrm{~mm}, l=1 \mathrm{~cm}$ or $l=2 \mathrm{~cm}$. The accumulation of charge in the cell (4) was measured. The components pertaining to the injector part of the system for AFM-based fishing are highlighted with the dashed line.

The sequence of the experiments was as follows. The system was filled with water from a test tube (1) and washed with $\sim 10 \mathrm{ml}$ of analyzed liquid (water or protein solution). After washing, the liquid supply system remained filled with the analyzed liquid. Then, the analyzed liquid was evacuated from the measuring cell with a pipette, and subsequent control measurements of the baseline signal for the empty cell (3 repetitions) were conducted. After that, the pump was turned on, and either water or 
protein solution was dropped into the measuring cell. The registration began at the moment when the pump was turned on. The data were recorded every $15 \mathrm{~s}$ during the measurement ( 5 to $7 \mathrm{~min}$ ). After the measurements within one experiment were completed, the electrometer indications were reset. The obtained data were presented in the form of averaged time dependencies of values of charge entering the measuring cell $\Delta q(t)$. If high variation between the obtained $\Delta q(t)$ dependencies was observed in one set, the data obtained in additional experiments were presented to find out the repeatability. The experiments were carried out under normal conditions without using external electromagnetic shielding of the injection part of the AFM-based fishing system. The electronic measurement circuit (including the measuring cell) was shielded from electromagnetic radiation to avoid interference.

\section{Results}

The influence of the following factors on the charge generation in the injector of the system for AFM-based fishing was studied:

1. The influence of mica and graphite AFM chips;

2. The influence of non-conductive polymer materials commonly used in fluidic communications in biosensors;

3. The influence of highly dilute protein solutions;

4. The influence of the external low-frequency electric field.

We first consider the influence of AFM chip materials on charge generation in the injector.

\subsection{Influence of AFM Chip Materials on Charge Generation}

\subsubsection{Influence of Mica AFM Chip on Charge Generation in Water Flow}

Firstly, generation of charge in the system for AFM-based fishing and its accumulation in the cell upon pumping of water through the injector with a peristaltic pump in the absence of an AFM chip was monitored. After that, a mica chip was placed at either $l=4 \mathrm{~mm}, l=1 \mathrm{~cm}$ or $l=2 \mathrm{~cm}$ distance from the injector nozzle, and charge measurements were performed. The obtained $\Delta q(t)$ dependencies are presented in Figures 2 and 3.

Figure 2 displays typical time dependencies ( $\Delta q(t)$ dependencies) of charge accumulation in the measuring cell obtained in the absence and in the presence of mica chip placed at $l=4 \mathrm{~mm}$ distance from the injector nozzle. The inset in this figure displays typical $\Delta q(t)$ dependencies obtained in a series of experiments upon pumping of water through the injector.

One can note slight variations between $\Delta q(t)$ obtained in the absence of mica chip (see inset). The charge accumulation rate without mica was 42 to $44 \mathrm{nC}$ in $7 \mathrm{~min}$, the average value was $(43 \pm 1)$ $\mathrm{nC}$ in $7 \mathrm{~min}$. In the presence of mica chip, an increase in charge accumulation rate was observed in comparison with the case without mica. An increased level of charge accumulation ( 53 to $57 \mathrm{nC}$ ) was observed, with an average value of $(55 \pm 2) \mathrm{nC}$ in $7 \mathrm{~min}$. Also, one can note an insignificant variation between $\Delta q(t)$ obtained in the presence of mica chip (see inset). Thus, in the main graph in Figure 2, averaged $\Delta q(t)$ dependencies are presented. As seen from Figure 2, an increased rate of charge accumulation is observed when a mica AFM chip is placed near the injector nozzle-as compared to the case without the chip. The accumulation of the generated charge in the measuring cell was linearly dependent on time.

When the distance between the injector nozzle and chip was $10 \mathrm{~mm}$, analogously to the case with $l=4 \mathrm{~mm}$, an increased level (in comparison with the case without mica chip) of charge accumulation ( 48 to $50 \mathrm{nC}$ ) was observed. In a series of three repeated experiments, an average value of $(49 \pm 1) \mathrm{nC}$ in $7 \mathrm{~min}$ was obtained (Figure 3). Figure 3 displays averaged $\Delta q(t)$ dependencies obtained in this series of experiments. 


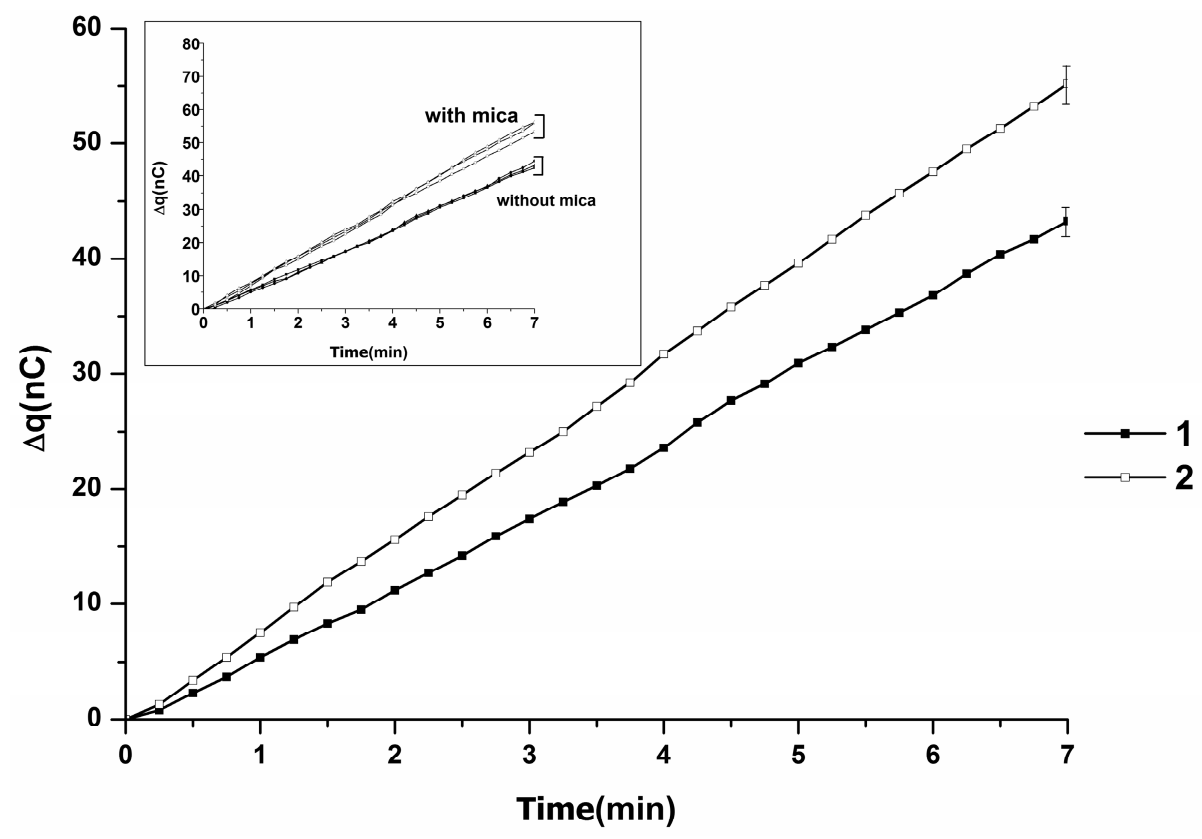

Figure 2. The effect of the presence of mica on the charge generation in water. Main graph presents averaged $\Delta q(t)$ dependencies obtained in a series of experiments: (1) without mica; (2) with mica. The inset displays typical $\Delta q(t)$ dependencies obtained in a series of experiments upon pumping of water through the injector. Experimental conditions: (1) without mica; (2) with mica. The distance between the injector nozzle and the mica chip is $l=4 \mathrm{~mm}$. T $=35^{\circ} \mathrm{C}$. The data of one and the same experimental series obtained using one and the same tube-pipe-tip set (see the Materials and Methods section) are presented.

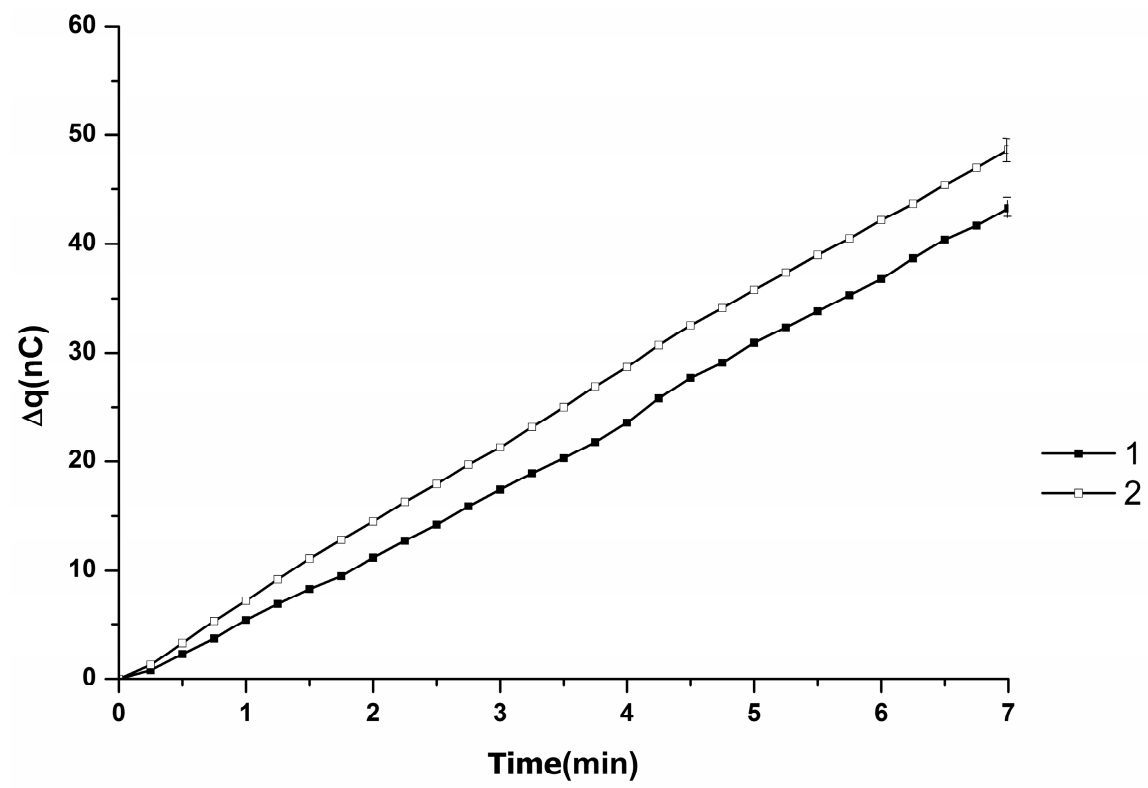

Figure 3. The influence of the presence of mica on the charge generation in water. Averaged $\Delta q(t)$ dependencies obtained upon pumping of water through the injector. Experimental conditions: (1) without mica; (2) with mica. The distance between the injector nozzle and the mica chip is $l=10 \mathrm{~mm} . \mathrm{T}=35^{\circ} \mathrm{C}$. The data of one and the same experimental series obtained using one and the same tube-pipe-tip set (see the Materials and Methods section) are presented.

Also, analogous experiments with the distance $l=2 \mathrm{~cm}$ were carried out. No significant influence of the mica chip on the charge generation was observed at this distance. 
Figure 4 displays the dependence of the relative change in the value of charge $(\Delta q / q)$ on the distance $l$ between the injector nozzle and the investigated material.

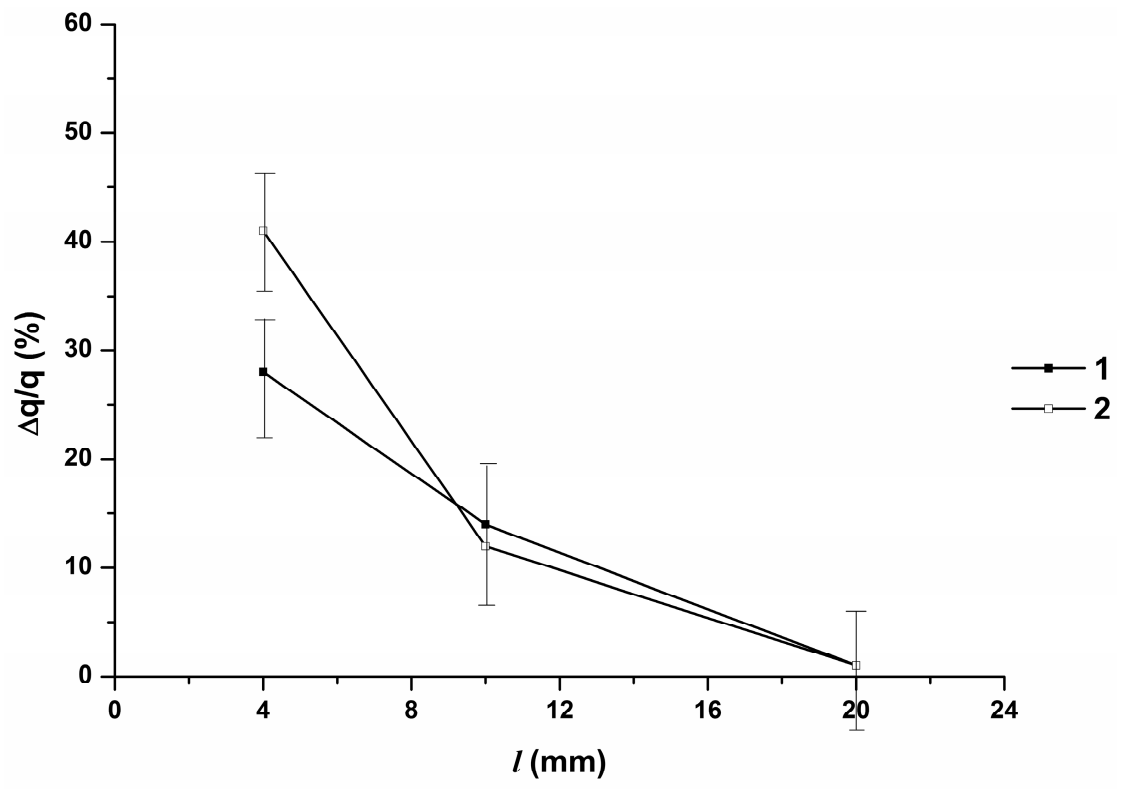

Figure 4. The dependencies of the relative change in the value of charge $(\Delta q / q)$, generated in water, on the distance between the injector nozzle and the investigated material: mica (1) or highly oriented pyrolytic graphite (HOPG) (2). $\mathrm{T}=35^{\circ} \mathrm{C}$.

As one can see from this figure, a decrease in the relative value of charge accumulated in the cell in the presence of the investigated material with increasing $l$ was observed. At $l=2 \mathrm{~cm}$, the relative change in the value of charge $(\Delta q / q)$, generated in water, does not differ from that measured in the absence of the investigated material.

Table 1 summarizes the numerical values of the relative increase in the charge generation rate in the presence of the mica chip near the injector nozzle. As seen from Table 1 (see Discussion section), the relative change in the value of charge accumulated in the cell in $7 \mathrm{~min}$ in the presence of mica chip at $l=4 \mathrm{~mm}$ makes up $\sim 28 \%$, while in the case of $l=10 \mathrm{~mm}$ this change is much less $(\sim 14 \%)$.

Table 1. Values of charge accumulated in the cell in the presence of various materials, $\mathrm{nC}$.

\begin{tabular}{ccc}
\hline Investigated Material & \multicolumn{2}{c}{$\Delta q / \boldsymbol{q}, \%$} \\
\hline Mica & $\boldsymbol{l} \mathbf{= 4} \mathbf{~ m m}$ & $\boldsymbol{l}=\mathbf{1} \mathbf{~ c m}$ \\
HOPG & 28 & 14 \\
polypropylene tube & 41 & 12 \\
polypropylene tube + water & - & 204 \\
polypropylene tube + BSA $\left(10^{-15} \mathrm{M}\right)$ & - & 33 \\
polypropylene tube $+\mathrm{BSA}\left(10^{-4} \mathrm{M}\right)$ & - & 33 \\
polypropylene tube $+\mathrm{C}_{2} \mathrm{H}_{5} \mathrm{OH}$ & - & 35 \\
\hline
\end{tabular}

$\Delta q / q$ is the relative change in the value of charge accumulated in the cell in the presence of an investigated material near the injector nozzle; $l$ is the distance between the material and the injector nozzle.

The charge of the mica chip was measured. The measured charge on mica surface was $-16 \mathrm{nC}$.

\subsubsection{Influence of HOPG AFM Chip on Charge Generation in Water Flow}

$\Delta q(t)$ dependencies were obtained in a repeated series of experiments in the absence and in the presence of HOPG chip near the tip nozzle. Insignificant variation between the obtained $\Delta q(t)$ curves 
were observed within this experimental series. For this reason, Figures 5 and 6 display averaged data $(\Delta q(t)$ dependencies) obtained in these experiments in the absence and in the presence of HOPG chip placed at either $l=4 \mathrm{~mm}$ (Figure 5) or $l=1 \mathrm{~cm}$ (Figure 6) distance from the injector nozzle.

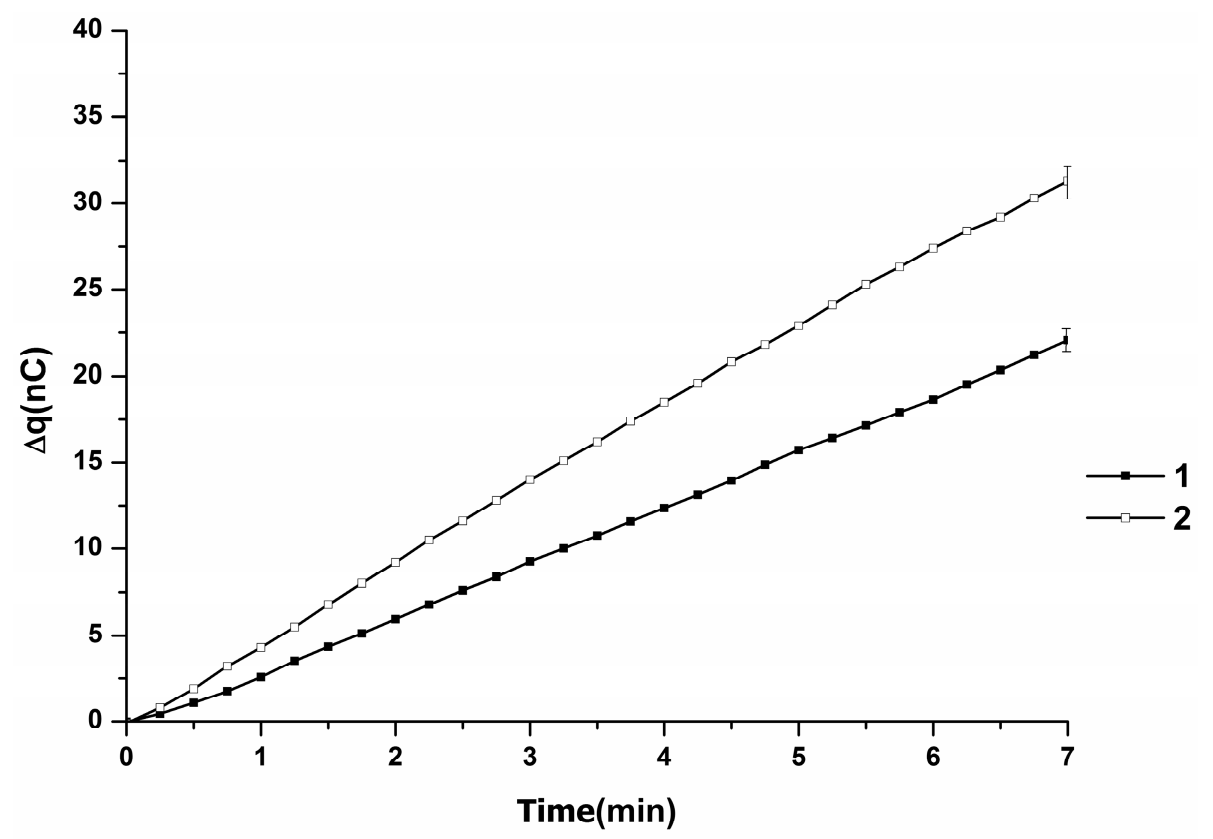

Figure 5. The effect of the presence of HOPG on the charge generation in water. Averaged $\Delta q(t)$ dependencies obtained upon pumping of water through the injector. Experimental conditions: without HOPG (1); with HOPG (2). The distance between the injector nozzle and the HOPG chip is $l=4 \mathrm{~mm}$. $\mathrm{T}=35^{\circ} \mathrm{C}$. The data of one and the same experimental series obtained using one and the same tube-pipe-tip set (see the Materials and Methods section) are presented.

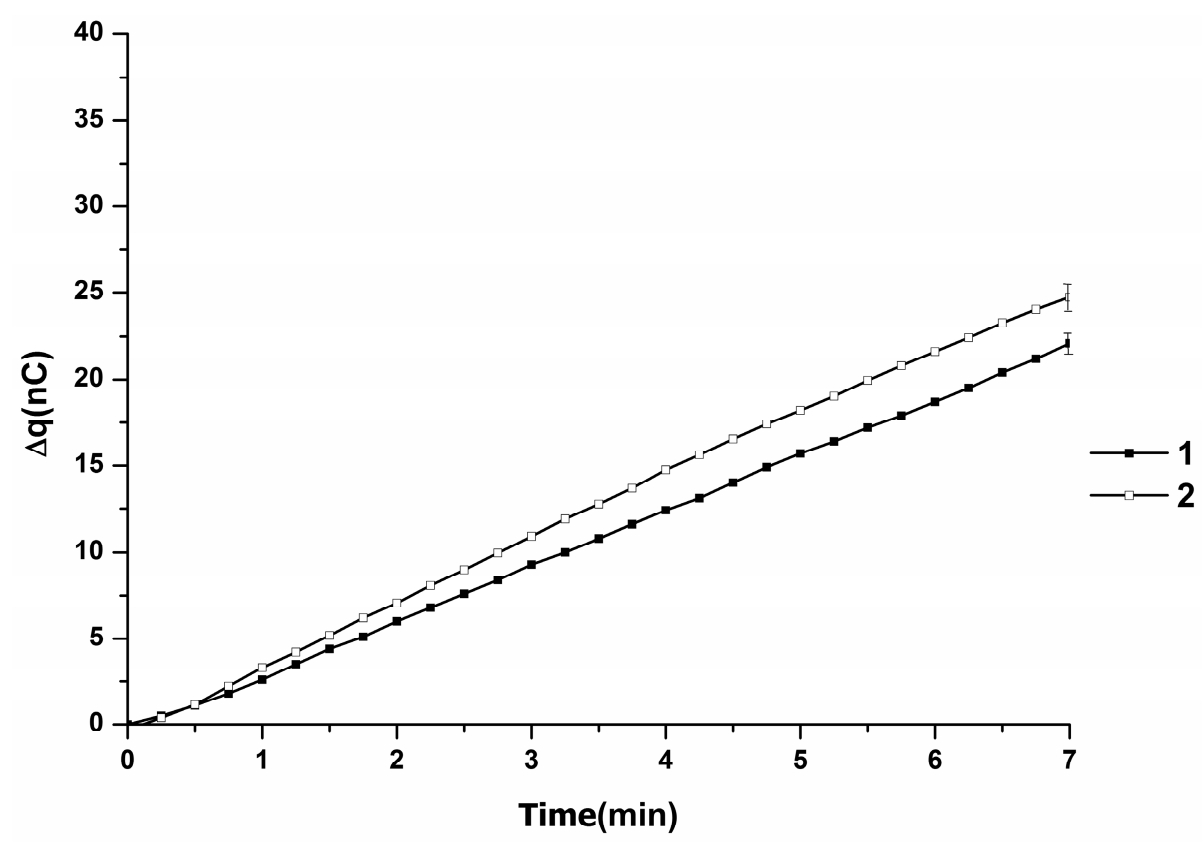

Figure 6. The effect of the presence of HOPG on the charge generation in water. Averaged $\Delta q(t)$ dependencies obtained upon pumping of water through the injector. Experimental conditions: without HOPG (1); with HOPG (2). The distance between the injector nozzle and the HOPG chip is $l=10 \mathrm{~mm}$. $\mathrm{T}=35^{\circ} \mathrm{C}$. The data of one and the same experimental series obtained using one and the same tube-pipe-tip set (see the Materials and Methods section) are presented. 
As seen from Figure 5, an increased rate of charge accumulation is observed when a HOPG AFM chip is placed near the injector nozzle-as compared to the case without the chip. The accumulation of the generated charge in the measuring cell was linearly dependent on time. The charge accumulation rate within the series of three repeated experiments without HOPG was 21 to $22 \mathrm{nC}$ in $7 \mathrm{~min}$, the average value was $(22 \pm 1) \mathrm{nC}$ in $7 \mathrm{~min}$. In the presence of HOPG, an increased level of charge accumulation ( 30 to $32 \mathrm{nC}$ ) was observed within the respective series of three repeated experiments, with an average value of $(31 \pm 1) \mathrm{nC}$ in $7 \mathrm{~min}$.

Figure 4 displays the dependence of the relative change in the value of charge, accumulated in the measuring cell, on the distance between the investigated material and the injector nozzle $(\Delta q / q(l)$ dependence). From the data presented in this figure, one can see that at $l=2 \mathrm{~cm}$ no influence (within the error) of the presence of the HOPG chip on the charge generation is observed.

Table 1 (see the Discussion section) lists the values of the relative change $(\Delta q / q)$ in the charge accumulated in the cell in the presence of various materials near the injector nozzle. In the case of HOPG, $\Delta q / q$ values were $41 \%$ and $12 \%$ at $l=4 \mathrm{~mm}$ and $l=1 \mathrm{~cm}$, respectively-that is, a decrease in the influence of HOPG on charge generation with increasing the distance between the HOPG chip and the injector was observed.

\subsection{The Influence of Non-Conductive Materials on Charge Generation in Water Flow}

Let us consider the influence of non-conductive materials on charge generation in water flow.

\subsubsection{The Influence of Polypropylene Tube on Charge Generation in the Flow-based System}

Experiments on monitoring of the generation and accumulation of charge in a flow-based system were carried out in the presence of a polypropylene tube. The tube was either empty or filled with water, ethanol or protein solution.

Empty Polypropylene Tube

The generation of charge in the system for AFM-based fishing and its accumulation in the cell upon pumping of water through the injector with a peristaltic pump at $\mathrm{T}=35^{\circ} \mathrm{C}$ in the presence of an empty polypropylene tube near the injector nozzle was monitored. At the distance $l=4 \mathrm{~mm}$, the trajectory of water drops falling from the injector nozzle into the cell bended from the vertical direction towards the polypropylene tube, and the drops adhered to the tube wall. For this reason, it was impossible to measure the charge accumulation in the cell in these conditions.

Figure 7 displays averaged time dependencies of charge accumulation in the measuring cell in the absence of the polypropylene tube, as the variation between the $\Delta q(t)$ observed within the corresponding series of three experiments was insignificant. The averaged dependencies for the case when the tube was placed at a distance $l=1 \mathrm{~cm}$ from the injector nozzle are also presented in this figure.

An increase in the rate of charge accumulation is observed, when an empty polypropylene tube was placed near the injector nozzle-as compared to the case without the tube. The charge accumulation rate within the series of three repeated experiments without the polypropylene tube was 26 to $28 \mathrm{nC}$ in $7 \mathrm{~min}$, the average value was $(27 \pm 1) \mathrm{nC}$ in $7 \mathrm{~min}$. In the presence of the polypropylene tube, an increased level of charge accumulation ( 77 to $86 \mathrm{nC}$ ) was observed within the respective series of three repeated experiments, with an average value of $(82 \pm 4) \mathrm{nC}$ in $7 \mathrm{~min}$, and the time dependence was linear.

Table 1 (see Discussion section) lists the data obtained when a polypropylene tube was placed at a distance $l=1 \mathrm{~cm}$ from the injector nozzle. As seen from Table 1 , the relative change in the value of charge accumulated in the cell in $7 \mathrm{~min}$ in the presence of an empty polypropylene tube makes up $204 \%$.

The charge on an empty polypropylene tube was measured. The measured charge on an empty polypropylene tube was $-24 \mathrm{nC}$. 


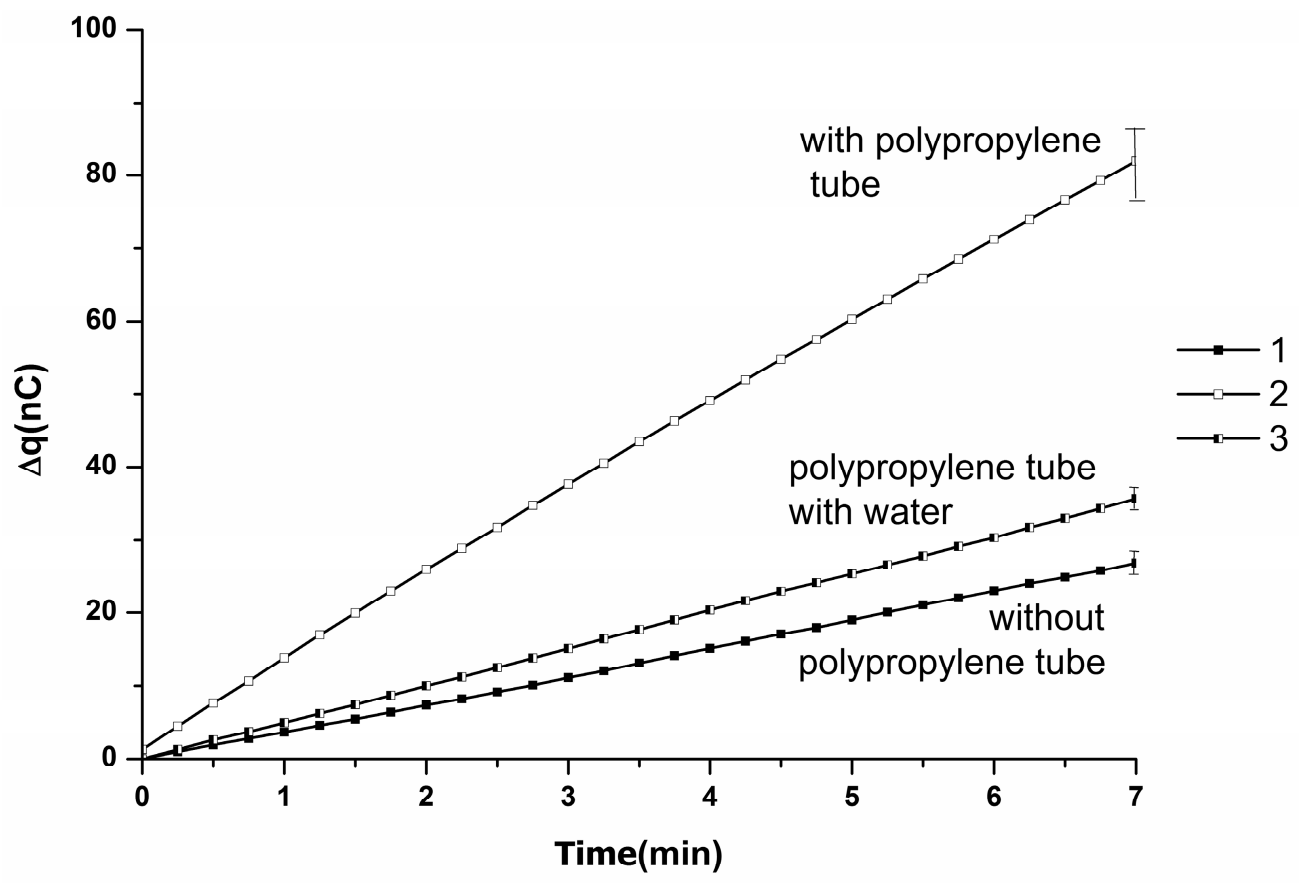

Figure 7. The effect of the presence of an empty polypropylene tube on the charge generation in water. Averaged $\Delta q(t)$ dependencies obtained upon pumping of water through the injector. Experimental conditions: (1) without polypropylene; (2) with polypropylene tube; (3) polypropylene tube filled with water. The distance between the injector nozzle and the polypropylene tube is $l=10 \mathrm{~mm}$. T $=35^{\circ} \mathrm{C}$. The data of one and the same experimental series obtained using one and the same tube-pipe-tip set (see the Materials and Methods section) are presented.

Polypropylene Tube Filled with Water, Protein Solution or Ethanol

The influence of a polypropylene tube filled with either water, protein solution $\left(10^{-4} \mathrm{M}\right.$ and $10^{-15}$ M BSA) or $96 \%$ ethyl alcohol (which are used as model solutions in nanobiosensors) was measured.

\section{Water-Filled Polypropylene Tube}

The generation of charge in the system for AFM-based fishing and its accumulation in the cell upon pumping of water through the injector with a peristaltic pump in the presence of a water-filled polypropylene tube, placed at a distance $l=1 \mathrm{~cm}$ from the injector nozzle, was monitored.

Figure 8 displays averaged time dependencies of charge accumulation in the measuring cell obtained when a polypropylene tube was placed at a distance $l=1 \mathrm{~cm}$ from the injector nozzle.

As seen from Figures 7 and 8, an increase in the rate of charge accumulation is observed when a water-filled polypropylene tube is placed near the injector nozzle-as compared to the case without the tube. At the same time, this increase is less pronounced than in the case with an empty polypropylene tube.

The charge accumulation rate within the series of repeated experiments in the absence of the water-filled polypropylene tube was 26 to $28 \mathrm{nC}$ in $7 \mathrm{~min}$, the average value was ( $27 \pm 1) \mathrm{nC}$ in $7 \mathrm{~min}$. In the presence of the water-filled polypropylene tube (placed at a distance $l=1 \mathrm{~cm}$ from the injector nozzle), an increased level of charge accumulation ( 35 to $36 \mathrm{nC}$ ) was observed within the respective experimental series, with an average value of $(36 \pm 1) \mathrm{nC}$ in $7 \mathrm{~min}$, and the time dependence was linear. Table 1 (see Discussion section) lists relative data on the charge generation obtained when the water-filled polypropylene tube was placed at a distance $l=1 \mathrm{~cm}$ from the injector nozzle. As seen from these data, the increase in the value of charge accumulated in the cell in $7 \mathrm{~min}$ in the presence of the water-filled polypropylene tube, was 33\%.

The charge on a water-filled polypropylene tube was measured. The measured charge of a water-filled polypropylene tube was $-6 \mathrm{nC}$. 


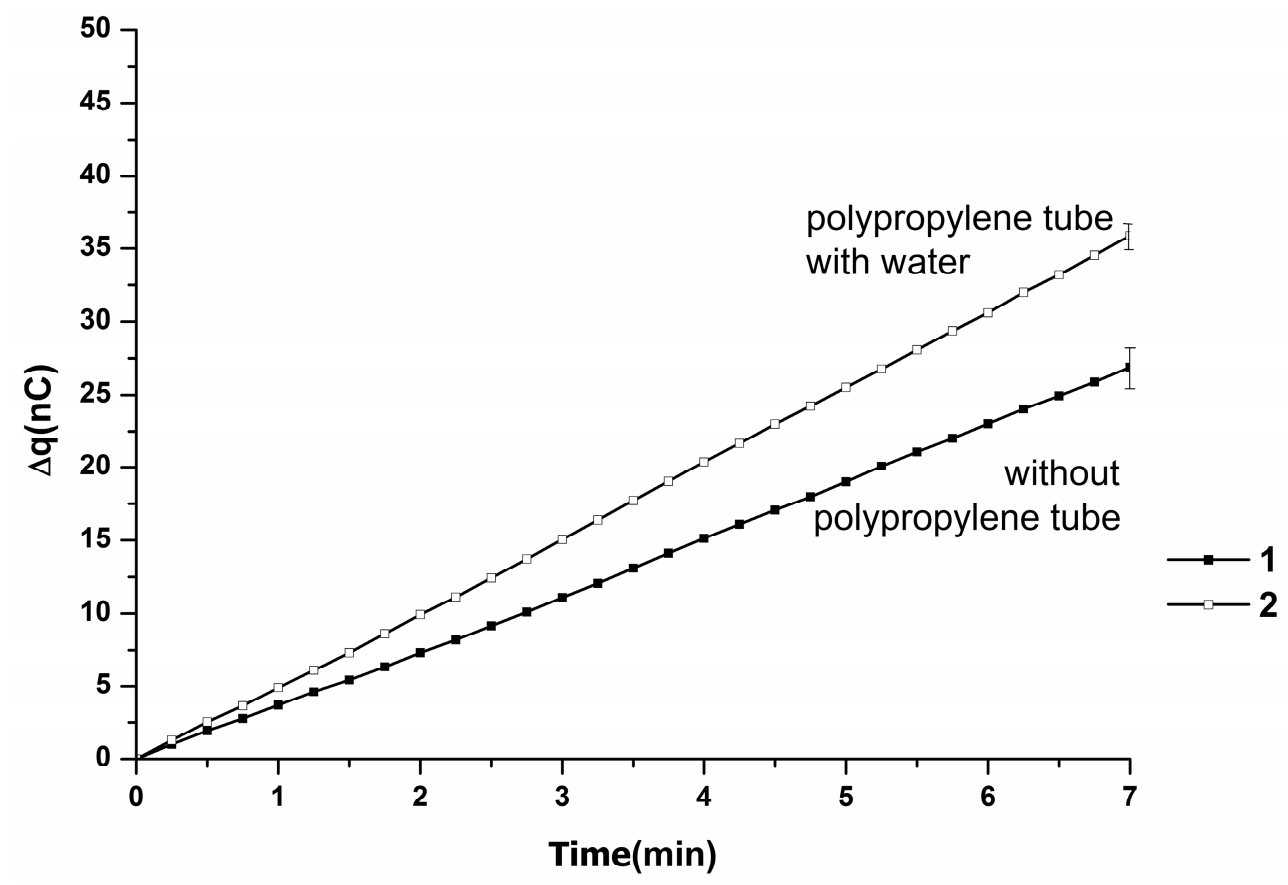

Figure 8. The effect of the presence of a water-filled polypropylene tube on the charge generation in water. Averaged $\Delta q(t)$ dependencies obtained upon pumping of water through the injector. Experimental conditions: (1) without the water-filled polypropylene tube; (2) with the water-filled polypropylene tube. $\mathrm{T}=35^{\circ} \mathrm{C}$. The distance between the injector nozzle and the polypropylene tube is $l=10 \mathrm{~mm}$. The data of one and the same experimental series obtained using one and the same tube-pipe-tip set (see the Materials and Methods section) are presented.

\section{Polypropylene Tube Filled with Protein Solution or Ethyl Alcohol}

In the presence of a polypropylene tube filled with protein solution or ethyl alcohol and placed at a distance $l=1 \mathrm{~cm}$ from the injector nozzle, the obtained results were similar to those obtained for a water-filled tube. The data obtained are listed in Table 1 (see Discussion section). The measured value of charge of a polypropylene tube filled with protein solution and ethyl alcohol were $-6 \mathrm{nC}$ and $-5 \mathrm{nC}$, respectively.

\subsection{The Influence of a Highly Dilute Protein on the Stimulation of Charge Generation in Flow-Based Biosensors}

Several sets of experiments were carried out. In these experiments, we have found that, along with linear ones, linear-stepwise $\Delta q(t)$ dependencies can also be observed both in the absence and in the presence of protein. In Figures 9 and 10, characteristic $\Delta q(t)$ dependencies for both these variants-linear-stepwise and linear dependencies-are presented. For the first variant, characteristic linear-stepwise dependencies are presented in Figure 9.

Figure 9 (with an inset) displays typical time dependencies of charge accumulation in the measuring cell obtained upon flow of water in the presence of BSA protein at $10^{-15} \mathrm{M}$ concentration (at which highly sensitive biosensors operate) and in the absence of the protein. The data presented in the inset indicate that linear-stepwise dependencies are observed. Such a stepwise change (by $1 \mathrm{nC}$, i.e., a $~ 30 \%$ increase) is observed, particularly, on one of the curves (obtained in the absence of the protein) at the time point $t=2.5 \mathrm{~min}$. In the presence of the protein, such stepwise changes are observed on all curves (for instance, at $t=3.5 \mathrm{~min}$ ). That is, the stepwise changes are observed both in the absence and in the presence of protein. The main graph in Figure 9 demonstrates that, after averaging, an increasing time dependence of charge accumulation was observed. 


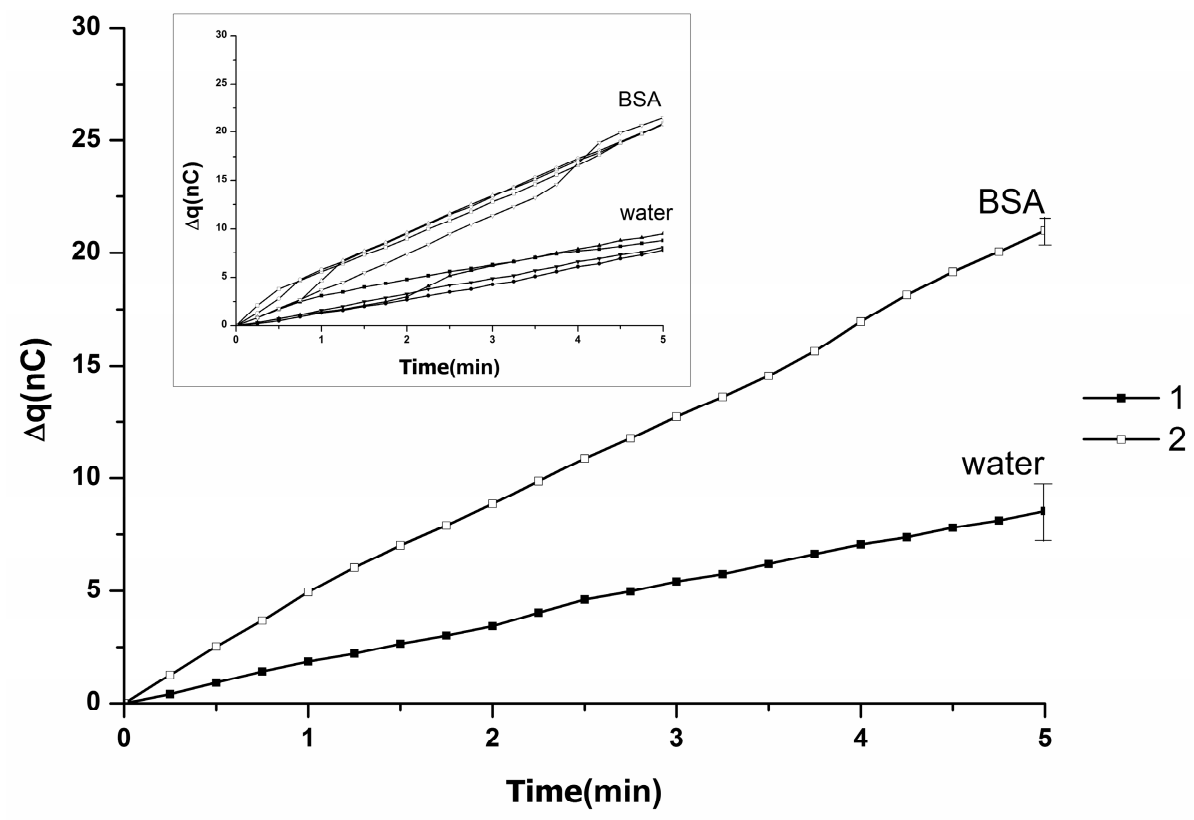

Figure 9. The effect of the presence of bovine serum albumin (BSA) protein on the charge generation in water. Averaged $\Delta q(t)$ dependencies obtained upon flow of water through the injector nozzle in the absence and in the presence of $10^{-15} \mathrm{M}$ BSA. Main graph presents averaged $\Delta q(t)$ dependencies obtained in a series of experiments: (1) without BSA (2) with BSA. Inset displays typical $\Delta q(t)$ dependencies obtained in a series of experiments upon pumping of water through the injector. Experimental conditions: (1) without BSA ("water"); (2) with BSA ("BSA"). T = $35{ }^{\circ} \mathrm{C}$. The data of one and the same set of experiments obtained using one and the same tube-pipe-tip set (see the Materials and Methods section) are presented.

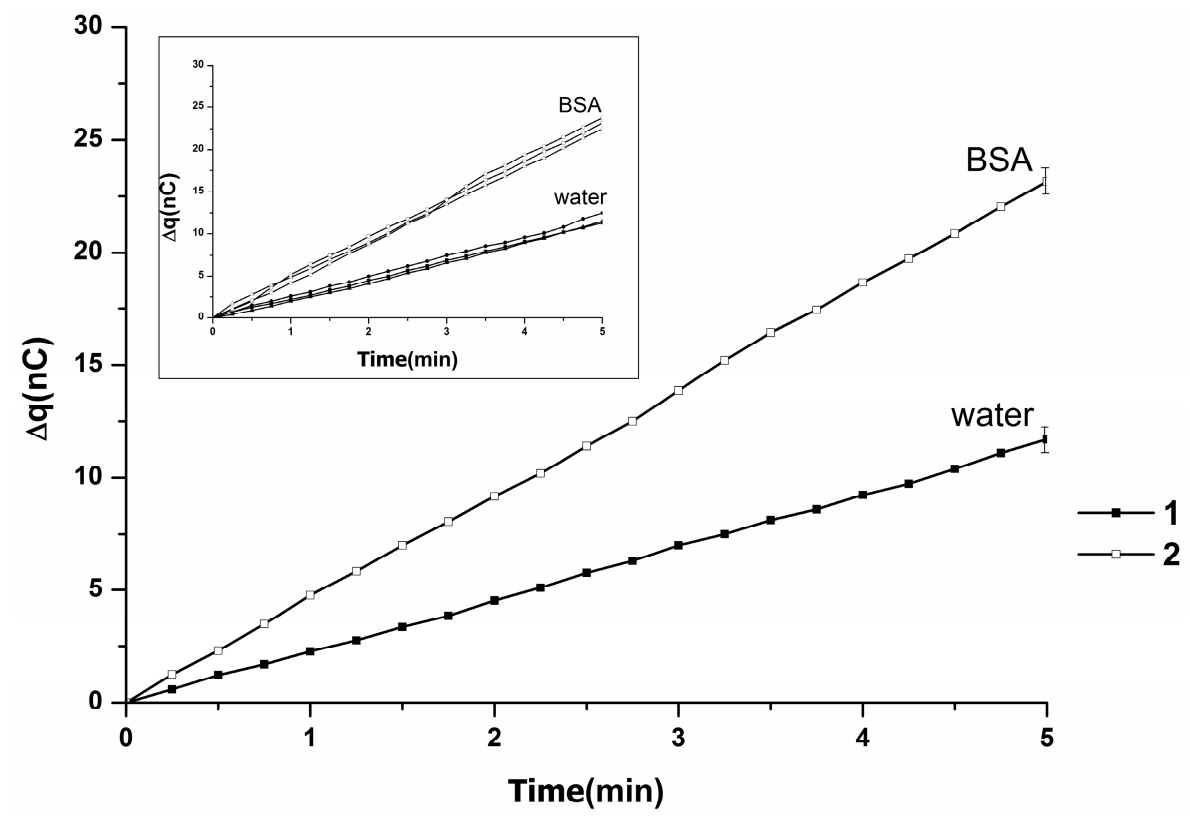

Figure 10. The effect of the presence of BSA protein on the charge generation in water. Averaged $\Delta q(t)$ dependencies obtained upon flow of water through the injector nozzle in the absence and in the presence of $10^{-15} \mathrm{M}$ BSA. Main graph presents averaged $\Delta q(t)$ dependencies obtained in experiments without BSA (1) and with BSA (2). Inset displays typical $\Delta q(t)$ dependencies obtained in a series of experiments upon pumping of water through the injector. Experimental conditions: (1) without BSA ("water"); (2) with BSA ("BSA"). T $=35^{\circ} \mathrm{C}$. The data of one and the same set of experiments obtained using one and the same tube-pipe-tip set (see the Materials and Methods section) are presented. 
As seen from the main graph in Figure 9, in the presence of BSA, an increase in the rate of generation of charge and its accumulation in the measuring cell from $9 \pm 1 \mathrm{nC}$ (in the absence of the protein) to $(21 \pm 1) \mathrm{nC}$ (in the presence of the protein)—-that is, by $(133 \pm 15) \%$-was observed. Thus, a stimulating influence of the presence of protein on the charge generation in water was observed.

Typical purely linear variant of characteristic $\Delta q(t)$ dependencies, obtained in one of the sets of experiments, is presented in Figure 10.

In Figure 10, the main graph presents averaged $\Delta q(t)$ dependencies obtained in a series of experiments: (1) without BSA, and (2) with BSA. The Inset displays typical $\Delta q(t)$ dependencies obtained in a series of experiments upon pumping of water (either with or without BSA) through the injector. As seen from the main graph in Figure 10, in the presence of BSA, an increase in the rate of generation of charge and its accumulation in the measuring cell from $(12 \pm 1) \mathrm{nC}$ (in the absence of the protein) to $(23 \pm 1) \mathrm{nC}$ (in the presence of the protein) - that is, by $(92 \pm 10) \%$-is observed. Thus, a stimulating influence of the presence of protein on the charge generation in water is observed, when $\Delta q(t)$ dependence was linear.

Eight sets of experiments were carried out. In all these experiments, a tendency for the rate of charge accumulation in the cell to increase in the presence of protein was always observed, as compared to the case with pure water. The averaged value of the stimulation of charge accumulation rate in the presence of the protein, obtained in these eight sets of experiments, makes up $(80 \pm 40) \%$.

\subsection{The Influence of an External Low-frequency Electric Field on the Charge Generation}

Two sets of experiments in the presence of external electric field were carried out. The experiments performed demonstrated that linear-stepwise time dependencies of charge accumulation in the cell $\Delta q(t)$ were observed along with linear ones, both in the absence and in the presence of an external electric field. In both sets of experiments, the obtained $\Delta q(t)$ dependencies exhibited linear-stepwise character. For this reason, in Figure 11 below we present only the data obtained in one set of these experiments.

Figure 11 displays typical time dependencies of charge generation and its accumulation in the measuring cell in the absence and in the presence of a $50 \mathrm{~Hz}$ external AC electric field. As an example, let us point out that, in the absence of the electric field, two curves in the inset demonstrate linear dependence of the accumulation of charge in the measuring cell, while two other curves in the inset exhibits linear-stepwise character. In the presence of the electric field, both linear and linear-stepwise $\Delta q(t)$ dependencies were also observed (see inset).

The main graph in Figure 11 displays the averaged time dependencies of charge generation and its accumulation in the measuring cell in the absence and in the presence of a $50 \mathrm{~Hz}$ external $\mathrm{AC}$ electric field.

As seen from Figure 11, an increase in the rate of generation of charge and its accumulation in the measuring cell from $(12 \pm 1) \mathrm{nC}$ (in the absence of an electric field) to $(19 \pm 2) \mathrm{nC}$ (in the presence of the field) - that is, by $(58 \pm 10) \%$-is observed. Thus, a low-frequency electric field causes an increase in the charge generation efficiency.

Averaging of the data obtained in two sets of experiments indicates that low-frequency electric field causes an increase in the charge generation efficiency by $(38 \pm 20) \%$. 


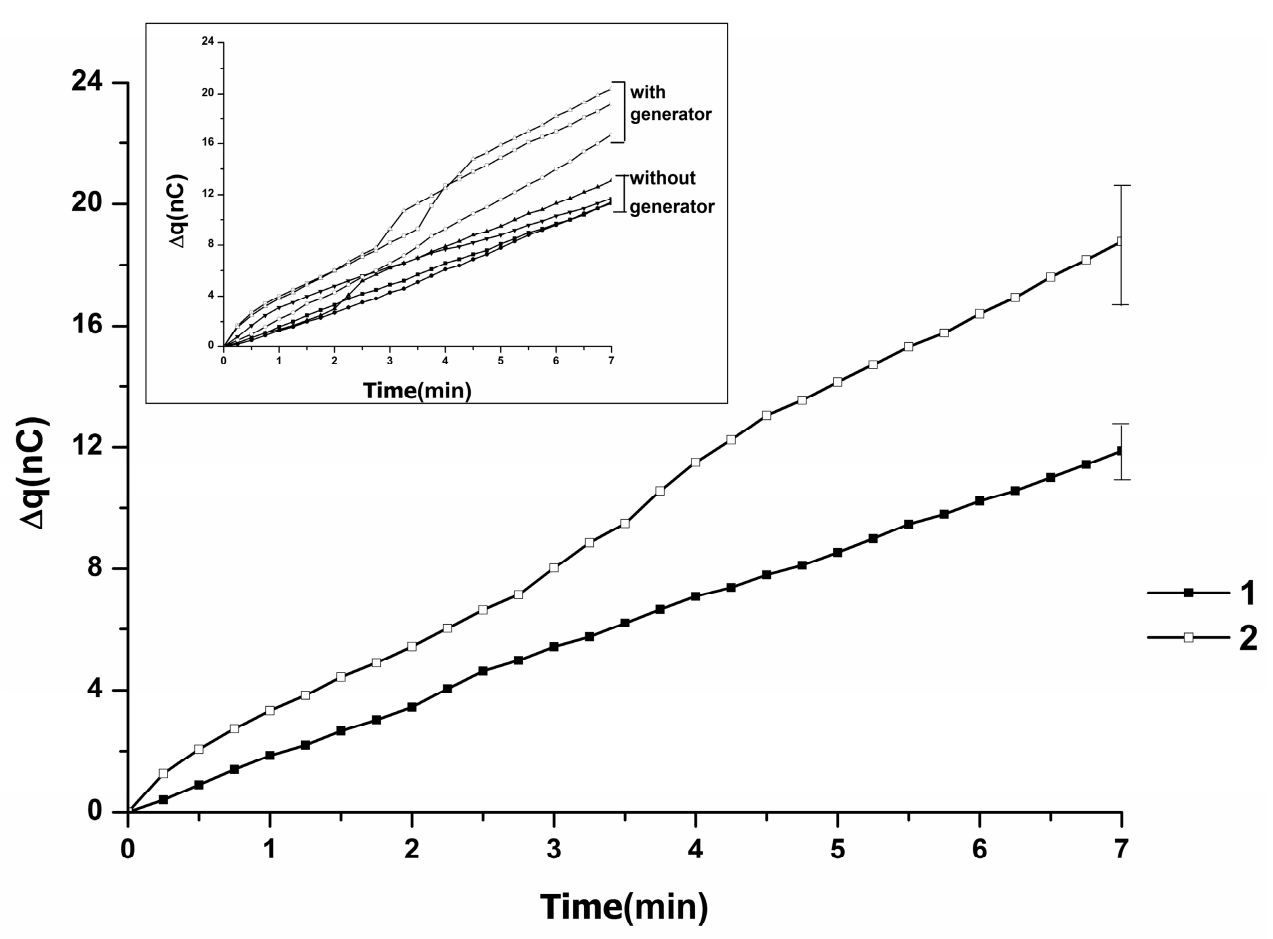

Figure 11. The effect of an external AC electric field on the charge generation in water. Averaged $\Delta q(t)$ dependencies obtained upon flow of water through the injector nozzle in the absence (1) and in the presence (2) of an external electric field. Main graph presents averaged $\Delta q(t)$ dependencies. Inset displays typical $\Delta q(t)$ dependencies obtained in experiments upon pumping of water through the injector. Experimental conditions: (1) in the absence of an external electric field ("without generator"); (2) in the presence of an external electric field ("with generator"). Experimental conditions: $\Delta U=-100 \mathrm{~V}$ voltage, $50 \mathrm{~Hz}$ frequency, $35^{\circ} \mathrm{C}$ temperature, $15 \mu \mathrm{L} / \mathrm{s}$ flow rate.

\section{Discussion}

It is known that electrokinetic phenomena, such as charge generation, are observed upon flow of water and aqueous solutions along the surface of polymer materials (for instance, polymethylmetacrylate, polytetrafluoroethylene, polystyrene, polyethylene, and polypropylene) [7,17].

In the literature, this fact is explained by the formation of an electric double layer and the motion of ions upon displacement of the liquid phase relative to the stationary one, when a pressure gradient is applied.

In Reference [7], a $\sim 0.1 \mathrm{nC}$ positive charge was registered upon pipetting of water through a plastic tip with an automatic pipette. It was reported that the pipette tip charged negatively, while the charge of the water drops was positive [7].

In our present study, an accumulation of a positive charge in the measuring cell has been observed upon flow of water at its continuous pumping with a peristaltic pump through the injector.

In our work, not only linear, but also linear-stepwise $\Delta q(t)$ dependencies have been observed in water. Examples of linear dependencies in water are demonstrated in Figure 2. Examples of linear-stepwise $\Delta q(t)$ dependencies are shown in Figures 9 and 10. Insignificant variation is observed between the data obtained in the series with linear $\Delta q(t)$ dependencies. Such slight variations between $\Delta q(t)$ curves can be caused by insignificant oscillations of the time dependence of charge accumulation due to the possible manifestation of electrokinetic effects associated with quantum-mechanical phenomena of spontaneous transitions of ortho-para states of water. The possibility of such transitions was discussed in Reference [15]. These transitions occur due to the fact that water is a non-equilibrium liquid in terms of spin temperature; and the equilibrium in water is shifted towards increasing the number of para-isomers of water. Thus, water is capable of changing the ortho-para ratio towards the equilibrium state [9] - particularly upon external influences. The efficiency of occurrence of these 
transitions should be more probable near water phase transition point at $\mathrm{T}=35^{\circ} \mathrm{C}$ to $37^{\circ} \mathrm{C}[9,18]$. These spontaneous transitions can be stimulated by the influence of a peristaltic pump on the water, flowing through the communications, as well as by other electrokinetic phenomena (such as flow of water through a tapering tip), as was noted in References [9]. Significant variations within one and the same series were observed for the cases when $\Delta q(t)$ dependencies were described by linear-stepwise curves. Occurrence of these linear-stepwise dependencies can be caused by an additional influence of external electromagnetic fields, which induce a change in the ratio between ortho- and para-isomers of water. Such influence was noted in the study by Pershin et al. [19], and possibly, also by other factors. Let us point out that linear-stepwise dependencies are observed not only in water, but also in aqueous protein solutions.

The data on the stimulation of the generation and accumulation of charge in relative units (i.e., relatively to the charge generated in the absence of the investigated material), obtained when the investigated material was placed near the injector nozzle, are summarized in Table 1.

As seen from Table 1, the mica chip placed near the injector caused an increase in efficiency of generation and accumulation of charge in the measuring cell (by $28 \%$ at $l=4 \mathrm{~mm}$ ). It is known that the mica surface was charged negatively, and our experiments demonstrated that this charge was about $-16 \mathrm{nC}$. The differences between $\Delta q(t)$ curves obtained in the presence of mica can be connected with causes of quantum-mechanical effects of transitions of ortho-para states of water near the critical point in external electromagnetic field. Upon the motion of water, an additional interaction of charged particles in water with the electric field occurs. This can lead to a number of effects, including additional effects on the motion of charged particles in water, and additional stimulation of transitions between ortho- and para-states of water. At that, with increasing $l$ from $4 \mathrm{~mm}$ to $1 \mathrm{~cm}$, this efficiency decreases twofold, to $14 \%$ (Figure 3).

We have measured the charge of an empty polypropylene tube, and it appeared to be of the same order of magnitude, $-24 \mathrm{nC}$. As seen from Table 1, the presence of a polypropylene tube also causes an increase in efficiency of generation and accumulation of charge (by $204 \%$ at $l=1 \mathrm{~cm}$ ). The diameter and the length of the polypropylene tube were $28 \mathrm{~mm}$ and $120 \mathrm{~mm}$, respectively, while the dimensions of the mica chip were $25 \mathrm{~mm} \times 75 \mathrm{~mm}$. That is, despite the dimensions of these materials being similar, the presence of the polypropylene tube caused a more pronounced effect. This is possibly connected with different electric field distribution near the injector caused by the difference in the materials' geometry, and accordingly, by the different capacity of the material/water-filled injector system. It is interesting to point out that filling of the polypropylene tube with water led to a decrease in the efficiency of charge accumulation in the measuring cell by almost an order of magnitude. Charge measurements in the system with the polypropylene tube have indicated that the value of charge accumulated in the cell also decreased by about an order of magnitude (from $-24 \mathrm{nC}$ to $-5 \mathrm{nC}$ ). Accordingly, with decrease in the charge, which induces external electric field, from $-24 \mathrm{nC}$ to $-5 \mathrm{nC}$, the influence of the electric field on the motion of charged particles in water decreases, and this leads to the observed effects. The system with the ethyl alcohol-filled polypropylene tube had a charge about $-5 \mathrm{nC}$, and the effect of such tube was approximately equal to that caused by water-filled tube.

When the tube was filled with $10^{-4} \mathrm{M}$ protein solution (whose concentration is approximately equal to the protein concentration in human blood [20]), the increase in the efficiency of charge accumulation in the measuring cell was approximately of the same level, as in the case of the tube filled with pure water. Here, it is to be noted that the charge of the polypropylene tube filled with protein solution was at the same level $(-6 \mathrm{nC})$.

Thus, one can conclude that the efficiency of generation and accumulation of charge in the measuring cell during the flow of liquid through the injector is influenced by the charge state of neighboring non-conductive mica and polymer surfaces: the efficiency of the generation of charge and its accumulation in the measuring cell increases with the increase in the value of negative charge of these surfaces. At that, the change in the capacity of the system in the presence of these surfaces also matters. 
Comparative experiments with protein solution and with water were carried out in eight sets. In all these sets, an effect of stimulation of the charge accumulation in the measuring cell has been observed in the presence of protein in water. The averaged data obtained in these eight sets of experiments have indicated that at $35^{\circ} \mathrm{C}$, the efficiency of charge generation in the pumped protein solution exceeded that in pure water by $\sim 80 \pm 40 \%$. This increase in charge generation efficiency is possibly caused by the fact that in protein solution, an increase in the fraction of ortho-state should be observed, what has resonant character at $\sim 35^{\circ} \mathrm{C}$, as was noted in Reference [18]. Possibly, in this case protein molecules at very low (femtomolar) concentration serve as catalysts of the transition of water in the interface layer from para- to ortho-state. The possibility of such transitions in aqueous heterogeneous structures in the presence of proteins was discussed in [21].

The influence of an external electromagnetic field $(50 \mathrm{~Hz})$ on the generation and accumulation of charge has also been investigated. As noted above, the influence of an external electric field (including the external electromagnetic environment) is supposed to be (as was noted above in this section) one of the causes of the variation between $\Delta q(t)$ curves. Industrial electrical networks typically operate at $50 \mathrm{~Hz}$ frequency. Upon the influence of an external low-frequency AC electric field at physiological temperatures of human body $\left(35^{\circ} \mathrm{C}\right)$, in all experiments, a tendency of the increase in the efficiency of generation and accumulation of charge was observed (Figure 11). The value of the increase in the generation and accumulation of charge, averaged over all the experimental sets, was $\sim 38 \%$. This increase in charge accumulation can be caused by a number of effects connected with the stimulating influence of an external AC electric field on the motion of charged particles in water, as well as on the quantum mechanical effects associated with the ratio between ortho- and para-isomers in moving water [19].

\section{Conclusions}

In our present study, the influence of mica and graphite AFM chips, and of polymer materials used in communications in systems for AFM-based fishing (which are used for the registration of low-abundant proteins at $35^{\circ} \mathrm{C}$ ) on the charge generation in a nanosystem for AFM-based fishing has been studied. It as shown that the presence of a graphite or mica chip near the injector nozzle enhances the effect of charge generation and its accumulation in the measuring cell. With the example of polypropylene, it was also demonstrated that polymer materials and/or communications can well influence the enhancement in the charge generation efficiency. At that, this efficiency depends on whether or not these communications are filled with water. It has been noted that the presence of protein at low (femtomolar) concentrations can lead to an increase in the efficiency of charge generation in the injector. It was demonstrated that low-frequency AC electric fields can well stimulate the charge generation in the injector. It was also shown that, along with linear time dependencies of charge accumulation, the occurrence of stepwise changes in the value of charge generated in the flow-based biosensor systems (in which liquid is pumped with a peristaltic pump through an injector) is possible.

These effects should be taken into account in the development of highly-sensitive nanobiosensors, whose sensitivity is significantly influenced by the charge state of proteins and protein solutions, and also in the development of specified models of effects occurring in biosensors.

Author Contributions: Conceptualization, Y.D.I.; Methodology, Y.D.I. and V.Y.T.; Validation, R.A.G. and V.S.Z.; Formal analysis, N.D.I.; Investigation, A.F.K., R.A.G. and V.S.Z.; Resources, V.Y.T.; Data curation, A.F.K., R.A.G., and N.D.I.; Writing—original draft preparation, Y.D.I. and A.F.K.; Writing—review and editing, Y.D.I.; Visualization, A.F.K.; Supervision, Y.D.I.; Project administration, Y.D.I.

Funding: The work was performed in the framework of the Program for Basic Research of State Academies of Sciences for 2013-2020.

Conflicts of Interest: The authors declare no conflict of interest. 


\section{References}

1. Rissin, D.M.; Kan, C.W.; Campbell, T.G.; Howes, S.C.; Fournier, D.R.; Song, L.; Piech, T.; Patel, P.P.; Chang, L.; Rivnak, A.J.; et al. Single-molecule enzyme-linked immunosorbent assay detects serum proteins at subfemtomolar concentrations. Nat. Biotechnol. 2010, 28, 595-599. [CrossRef] [PubMed]

2. Ivanov, Y.D.; Pleshakova, T.; Malsagova, K.; Kozlov, A.; Kaysheva, A.; Kopylov, A.; Izotov, A.; Andreeva, E.; Kanashenko, S.; Usanov, S.; et al. Highly sensitive protein detection by combination of atomic force microscopy fishing with charge generation and mass spectrometry analysis. FEBS J. 2014, 281, 4705-4717. [CrossRef] [PubMed]

3. Nettikadan, S.R.; Johnson, J.C.; Vengasandra, S.G.; Muys, J.; Henderson, E. ViriChip: A solid phase assay for detection and identification of viruses by atomic force microscopy. Nanotechnology 2004, 15, 383-389. [CrossRef]

4. Huff, J.L.; Lynch, M.P.; Nettikadan, S.; Johnson, J.C.; Vengasandra, S.; Henderson, E. Label-Free Protein and Pathogen Detection Using the Atomic Force Microscope. J. Biomol. Screen. 2004, 9, 491-497. [CrossRef] [PubMed]

5. Patolsky, F.; Zheng, G.; Hayden, O.; Lakadamyali, M.; Zhuang, X.; Lieber, C.M. Electrical detection of single viruses. Proc. Natl. Acad. Sci. USA 2004, 101, 14017-14022. [CrossRef] [PubMed]

6. Pleshakova, T.O.; Malsagova, K.A.; Kaysheva, A.L.; Kopylov, A.T.; Tatur, V.Y.; Ziborov, V.S.; Kanashenko, S.L.; Galiullin, R.A.; Ivanov, Y.D. Highly sensitive protein detection by biospecific AFM-based fishing with pulsed electrical stimulation. FEBS Open Bio 2017, 7, 1186-1195. [CrossRef] [PubMed]

7. Choi, D.; Lee, H.; Im, D.J.; Kang, I.S.; Kim, D.S.; Lim, G. Spontaneous electrical charging of droplets by conventional pipetting. Sci. Rep. 2013, 3, 2037. [CrossRef] [PubMed]

8. Touchard, G.; Patzek, T.W.; Radke, C.J. A physicochemical explanation for flow electrification in low-conductivity liquids. IEEE Trans. Ind. Appl. 1996, 32, 1051-1057. [CrossRef]

9. Pershin, S.M. Conversion of ortho-para $\mathrm{H} 2 \mathrm{O}$ isomers in water and a jump in erythrocyte fluidity through a microcapillary at a temperature of $36.6 \pm 0.3^{\circ} \mathrm{C}$. Phys. Wave Phenom. 2009, 17, 241-250. [CrossRef]

10. Ivanov, Y.D.; Kozlov, A.F.; Galiullin, R.A.; Tatur, V.Y.; Ziborov, V.S.; Usanov, S.A.; Pleshakova, T.O. Influence of a Pulsed Electric Field on Charge Generation in a Flowing Protein Solution. Separations 2018, 5, 29. [CrossRef]

11. Ivanov, Y.D.; Kozlov, A.F.; Galiullin, R.A.; Tatur, V.Y.; Ivanova, N.D.; Ziborov, V.S. Influence of AC electric field on the charge generation in albumin solution in a flow-based AFM fishing system. IOP Conf. Ser. Mater. Sci. Eng. 2018, 443, 012011. [CrossRef]

12. Burgo, T.A.; Galembeck, F.; Pollack, G.H.; Burgo, T.A.L. Where is water in the triboelectric series? J. Electrost. 2016, 80, 30-33. [CrossRef]

13. Ryzhkina, I.S.; Kiseleva, Y.V.; Murtazina, L.I.; Mishina, O.A.; Sherman, E.D.; Konovalov, A.I. Comparative study of self-organization and physicochemical properties of highly diluted aqueous solutions of phenol bioantioxidants. Dokl. Phys. Chem. 2012, 447, 203-206. [CrossRef]

14. Konovalov, A.; Ryzhkina, I.; Maltzeva, E.; Murtazina, L.; Kiseleva, Y.; Kasparov, V.; Palmina, N. Nanoassociate formation in highly diluted water solutions of potassium phenosan with and without permalloy shielding. Electromagn. Biol. Med. 2015, 34, 141-146. [CrossRef] [PubMed]

15. Ivanov, Y.D.; Kozlov, A.F.; Galiullin, R.A.; Tatur, V.Y.; Ziborov, V.S.; Ivanova, N.D.; Nikitaev, V.G.; Druzhinina, E.A.; Pleshakova, T.O. The Effect of Pulsed Electric Field on the Generation of Charge in Flow-Based Medical and Diagnostic Systems. Biomed. Eng. 2018, 52, 231-234. [CrossRef]

16. Mccarty, L.S.; Whitesides, G.M. Electrostatic Charging Due to Separation of Ions at Interfaces: Contact Electrification of Ionic Electrets. Angew. Chem. Int. Ed. 2008, 47, 2188-2207. [CrossRef] [PubMed]

17. Ivanov, Y.; Kozlov, A.; Galiullin, R.; Kanashenko, S.; Usanov, S.; Ivanova, N.; Ziborov, V.; Pleshakova, T. Spontaneous generation of charge in the flow-based AFM fishing system. J. Electrost. 2018, 91, 16-20. [CrossRef]

18. Kholmanskiy, A.S. Two Types of Anomalous Thermodynamics of Water. Apriori. Ser. Iestestv. I Tekh. Nauki 2015, 1, 1-17.

19. Pershin, S.M. New conception considering the impact of EMF on water/water solutions with account for quantum differences between ortho- and para-isomers of $\mathrm{H}_{2} \mathrm{O}$. Available online: http:/ / www.biophys.ru/ archive/sarov2013/proc-p17.pdf (accessed on 5 February 2019). 
20. Fasano, M.; Curry, S.; Terreno, E.; Galliano, M.; Fanali, G.; Narciso, P.; Notari, S.; Ascenzi, P. The extraordinary ligand binding properties of human serum albumin. IUBMB Life 2005, 57, 787-796. [CrossRef] [PubMed]

21. Bunkin, A.F.; Pershin, S.M. Coherent laser spectroscopy of hydration processes of biomolecules and nanoparticles. Trudy IOFAN 2013, 69, 58-70. 